\title{
RELIGIE ȘI POLITICĂ ÎN CONTEXTUL ASALTULUI DIN 6 IANUARIE 2021 ASUPRA CONGRESULUI SUA
}

\author{
Dr. Iulian DINULESCU*
}

In 6 ianuarie 2021, o mulțime furioasă a atacat forțele de securitate și a luat cu asalt Congresul Statelor Unite ale Americii, majoritatea purtând pancarte conținând simboluri creștine și manifestând o conduită ultrareligioasă. Mulțimea a scandat sloganuri și cântece religioase amestecate cu repere ideologic-politice extremiste, teorii conspiraționiste QAnon și atitudini rasiste. De asemenea, protestatarii au urmat un ritual aflat în Biblie, în Vechiul Testament, în cartea lui Iosua Navi, un lider israelit căruia Dumnezeu i-a indicat modul în care va cuceri Cetatea Ierihonului, plină de oameni corupți și desfrânați, dacă va asculta porunca divină. Participanții la asalt au urmat același ritual pentru a „,cuceri” cetatea Capitoliului cu o lună înainte și l-au repetat începând cu 5 ianuarie 2021.

Întrucât religia este credința în Dumnezeu și reprezintă relația dintre omul credincios și divinitate, însuşirea unor elemente de ideologie politică de către oamenii ultrareligioși a fost considerată naturală și obligatorie în conturarea unei societăți care să se dezvoltate pe principii creștine sub forma unei ,cetăți creștine".

In prezentul articol, prin analiza atitudinii comunității creștine în două faze distincte, cea de dinainte și, respectiv, cea din timpul și de după asaltul asupra Congresului SUA, vafirelevat rezultatul manifestăriifenomenului ultrareligiozității imbinat cu o ideologie politică extremistă.

Cuvinte-cheie: mișcarea QAnon; ultrareligiozitate; asaltul asupra Congresului SUA, politică extremistă; simboluri religioase; ideologie politicăa; teorii conspiraționiste.

*Iulian DINULESCU este doctor în Informații și Securitate Națională, Academia Naţională de Informații „Mihai Viteazul”, București. E-mail: iuliandinulescu@gmail.com 


\section{Introducere}

În diferite ocazii de-a lungul istoriei, credința religioasă a fost folosită ca justificare pentru săvârșirea unor violențe inițiate de practicanți ai acesteia în numele divinității. Astfel, prin crezurile religioase au fost justificate cele mai violente acțiuni; pentru adepții ultrareligioși credința lor fiind singurul lucru care contează, iar pentru cei care-l practică extremismul religios fiind considerat legitim din perspectivă proprie.

Astfel s-a întâmplat și în cazul asaltului asupra Congresului Statelor Unite ale Americii (SUA) la care au participat numeroase persoane ultrareligioase, o parte fiind exponenți ai unor grupuri și organizații de extremă dreapta sau a unora religioase. Aceștia aveau convingerea că nu au altă cale decât să ia cu asalt legislativul american și să-l împiedice să certifice alegerea în funcție a președintelui ales, Joseph Robinette Biden.

Sociologul Mark Juergensmeyer susține că „mulți dintre participanți erau creștini heterosexuali albi, supărați și afectați de promovarea multiculturalismului fără bariere în societate și de tendința statului de a deveni unul socialist, care va acorda tuturor cetățenilor ajutoare sociale..., simțindu-se înstrăinați și umiliți într-o nouă ordine mondială care nu ține cont de ei”’1.

Mai mult, în asaltul asupra Congresului SUA au participat persoane ultrareligioase care aveau convingerea fermă că sunt ,participante la un fel de război sfânt"'. De altfel, unii dintre aceștia au recunoscut că au parcurs distanțe semnificative, de mii de kilometri, pentru a participa la proteste, întrucât au primit un „semn de la Dumnezeu” și au fost încurajați de pastorii congregațiilor din care făceau parte să „oprească furtul”. ${ }^{3}$ Opinia unora dintre aceștia era că lupta se duce între bine și rău, întuneric contra lumină ${ }^{4}$, justificându-și astfel participarea la această acțiune. De altfel, Tom Gjelten, un cercetător al fenomenului spune: „Creștinii naționaliști și militanți sunt o forță puternică în societate, iar pe fondul unor convingeri politice profunde resping realitatea înconjurătoare și, ca orice fanatic, devin violenți’’s. Alți autori sunt de părere că un astfel de fenomen nu este

\footnotetext{
${ }^{1}$ Mark Juergensmeyer, ,The three qualities marking the Capitol assault as terrorism”, în Religion Dispatches, 8 ianuarie 2021, URL: https://religiondispatches.org/the-three-qualities-marking-thecapitol-assault-as-terrorism/, accesat la 08.03.2021.

${ }^{2}$ Elizabeth Dias, Ruth Graham, „How White Evangelical Christians Fused With Trump Extremism A potent mix of grievance and religious fervor has turbocharged the support among Trump loyalists, many of whom describe themselves as participants in a kind of holy war", în The New York Times, 19 ianuarie 2021, URL: https://www.nytimes.com/2021/01/11/us/how-white-evangelical-christiansfused-with-trump-extremism.html, accesat la 12.03.2021.

${ }^{3}$ Ibidem.

${ }^{4}$ Ibidem.

${ }^{5}$ Tom Gjelten, „Militant Christian Nationalists Remain a Potent Force, Even after the Capitol Riot”,
} 
nou și nu a apărut intempestiv, ci s-a dezvoltat în ultimii ani pe fondul unui ,amestec puternic de nemulțumiri și fervoare religioasă’’

Pe un asemenea fond de nemulțumire generalizată nelocalizată în mod clar, prin prezentarea unor argumente aparent solide care să le sprijine acuzațiile, cu îmbinarea unor teorii conspiraționiste QAnon (fraudarea alegerilor, existența statului paralel abuzator de copii și corupt etc.) cu precepte religioase ancorate în Biblie și ideologie politică, la toate acestea achiesând nu numai creștini naționaliști, ci și grupuri și organizații de extremă dreapta, era inevitabil ca exponenții fenomenului să declanșeze violențe și să intre în conflict cu autoritățile. Mai gravă și cu repercusiuni pe termen scurt și mediu este convingerea deplină a exponenților unui astfel de fenomen că este dreptul lor divin să creeze o societate așa cum o văd ei din propria perspectivă, fără a ține cont de doleanțele celorlalți.

\section{Atitudinea membrilor unor congregații creștine inainte de asaltul asupra Congresului SUA}

$\mathrm{Cu}$ doar câteva zile înainte de investirea noului președinte american Joseph Robinette Biden, în 20 ianuarie 2021, Darryl Knappen, pastorul congregației creștine Cornerstone Church din Alexandria, statul Minnesota, refuza să accepte alegerea democratică a acestuia și ,chiar se declara dispus să ia armele” pentru a-1 susține pe președintele încă în funcție Donald Trump. Într-o postare pe Facebook, clericul asemăna situația actuală din SUA cu cea din timpul revoluției americane din urmă cu peste două sute de ani. „Pastorii au fost cei care au condus calea în timpurile coloniale pentru a încuraja țara noastră să se scuture de regimul totalitar al regelui Angliei”, spunea clericul făcând trimitere la „Regimentul Robelor Negre”, numele dat pastorilor care au susținut și s-au implicat activ în războiul de independență a Statelor Unite ale Americii față de Regatul Marii Britanii. ${ }^{7}$

Franklin Graham, unul dintre liderii unei congregații religioase importante, previziona cu 4 luni înainte de asaltul asupra Congresului SUA ceea ce avea să se întâmple. Astfel, în 28 august 2020, acesta spunea „cred că Dumnezeu 1-a adus aici pentru acest termen, pentru acești patru ani”", referindu-se la Donald Trump, președintele în exercițiu la acea dată. Tot Graham afirma „,...Cred că vine furtuna. Veți vedea creștini atacați, veți vedea biserici închise; veți vedea o ură

în NPR, 19 ianuarie 2021, URL: https://www.npr.org/2021/01/19/958159202/militant-christiannationalists-remain-a-potent-force, accesat la 06.03.2021.

${ }^{6}$ Elizabeth Dias, Ruth Graham, art. cit.

${ }^{7}$ Tom Gjelten, art. cit.

${ }^{8}$ David Brody, „Exclusive: Franklin Graham Tells CBN News He Thinks Democratic Party is 'Opposed to Faith", în CBN News, 28.08.2020, URL: https://www1.cbn.com/cbnnews/2020/ august/exclusive-franklin-graham-tells-news-he-thinks-democrats-are-opposed-to-faith, accesat la 06.03.2021. 
reală exprimată față de oamenii de credință. Asta vine" . Participanții religioși la asaltul asupra Capitoliului aveau convingerea că „Dumnezeu 1-a uns” pe Donald Trump să conducă SUA și că numirile făcute de acesta în poziții cheie în stat făceau parte dintre obiectivele subsumate restaurării „SUA ca națiune creștină”. Ulterior alegerilor prezidențiale și a câștigării acestora de către Joe Biden, aceștia și-au manifestat loialitatea „faţă de liderul lor divin"

Referitor la acumularea tensiunii în sânul unor comunități creștine, Jerushah Duford, nepoata predicatorului american defunct Billy Graham, a afirmat că ceea ce s-a întâmplat în 6 ianuarie 2021 a fost rezultatul unei tensiuni acumulate în rândul oamenilor religioși, dinainte de eveniment. ${ }^{11}$ De altfel, în săptămânile precedente evenimentului, au existat organizații care „au promovat o narațiune creștină belicoasă, în apărarea încercării de lovitură de stat a lui Trump și pentru a justifica un război sfânt împotriva unui stat ilegitim" ${ }^{2}$. Printre acestea se numără și grupul creștin Jericho March, înființat la finalul lunii noiembrie 2020, de doi angajaţi ai unor organizații creștine, Arina Grossu și Rob Weaver, având ca obiective „să protesteze cu rugăciune şi să solicite oficialilor guvernamentali să facă lumină asupra fraudei electorale, corupției și suprimării voinței poporului american în aceste alegeri"13. Implicarea grupului în asaltul asupra Capitoliului a evidențiat opusul declarațiilor lor, ca și organizarea în preambul a unui marș, în 12 decembrie 2020, în Washington, care a degenerat în violență. De asemenea, cu ocazia protestului, participanții au amalgamat teorii conspiraționiste și „strigăte de luptă cu apeluri la creștinism”14.

În aceeași nuanță, publicistul creștin și jurnalistul Eric Metaxas afirma în 9 decembrie 2020, la o emisiune radio: „Trebuie să facem absolut tot ce putem. Ce se va întâmpla se va întâmpla. Dar trebuie să luptăm până la moarte, până la ultima picătură de sânge, pentru că merită" ${ }^{15}$. Ulterior, în 12 decembrie 2020, Metaxas conducea adunarea religioasă denumită The Jericho March din Washington unde, împreună cu ceilalți participanţi, ,̂̂l implorau pe Dumnezeu să-l țină pe Trump în funcție" ${ }^{\prime \prime}$. Conform Declarației grupului Jericho March, din 14 ianuarie 2021, postat

\footnotetext{
${ }^{9}$ Ibidem.

${ }^{10}$ Sarah Posner, „How the Christian Right Helped Foment Insurrection - Christian-right activists inside and outside of government promoted the election fraud lie and claimed God told them to "let the church roar", în Rolling Stone, 31 ianuarie 2021, URL: https://www.rollingstone.com/culture/ culture-features/capitol-christian-right-trump-1121236/, accesat la 08.03.2021.

${ }^{11}$ Ed Pilkington, „Evangelical leaders condemn role of Christian nationalism în Capitol attack”, în The Guardian, 24 februarie 2021, URL: https://www.theguardian.com/world/2021/feb/24/evangelicalleaders-christian-nationalism-capitol-riot, accesat la 09.03.2021.

${ }^{12}$ Sarah Posner, art. cit.

${ }^{13}$ Ibidem.

${ }^{14}$ Ibidem.

${ }^{15}$ Tom Gjelten, art. cit.

${ }^{16}$ Ibidem.
} 
pe website-ul propriu, aceasta este o mișcare „pașnică de rugăciune în care oamenii de credință iudeo-creștină se roagă împreună, cântă cântece și suflă în shofare" ${ }^{\prime 17,18}$.

Robert Weaver, co-fondator al Jericho March, prezent la marșul din 12 decembrie 2020 prin care era replicat ritualul biblic care a avut loc asupra cetății Ierihonului, a afirmat către participanți că „Dumnezeu i s-a arătat într-o viziune după victoria alegerilor lui Biden și i-a spus: „Nu s-a terminat” ${ }^{19}$. La marș a fost prezent și Stewart Rhodes, fondatorul miliției OathKeepers, care a afirmat că ,speră că Trump va folosi Legea insurecției pentru a arunca ciocanul asupra adversarilor săi”20. Tot Rhodes spunea că Dumnezeu ,trebuie să știe” de la fiecare persoană în parte că este alături de El” și că „dacă nu o face acum, va trebui să o facem noi înșine mai târziu, într-un război mult mai disperat, mult mai sângeros". ${ }^{21}$

Pastorul Greg Locke ${ }^{22}$ afirma într-o carte publicată în septembrie 2020, având titlul „This Means War”, că „suntem la o singură alegere distanță”, referindu-se la alegerile prezidențiale din SUA din noiembrie 2020, „de a pierde tot ceea ce ne este drag”, iar lupta este ,împotriva a tot ceea ce este rău și păcătos în lume”. ${ }^{23}$ Aceasta este „o adunare a trupelor sfintei armate a lui Dumnezeu. Aceasta este ziua noastră. Acesta este timpul nostru. Aceasta înseamnă ceva pentru Regat. De altfel, acesta înseamnă război" ${ }^{24}$. Cu o zi înainte de asaltul asupra Capitolului, pastorul Greg Locke a scris pe platforma de socializare Twitter un mesaj prin care chema credincioșii în capitala americană: „Fie ca focul Duhului Sfânt să cadă peste Washington DC astăzi și mâine. Fie ca Mielul lui Dumnezeu să fie înălțat. Să se ridice Dumnezeu și duşmanii Săi să fie smeriți’”25; postarea nu mai este disponibilă

\footnotetext{
${ }^{17}$ Trâmbițe din coarne de berbeci utilizate de evreii antici în ceremoniile religioase, precum și ca semnal de luptă.

${ }^{18}$ Jericho March website, Statement from Jericho March, 14 ianuarie 2021.

${ }^{19}$ Tom Gjelten, art. cit.

${ }^{20}$ Ibidem.

${ }^{21}$ Ibidem.

${ }^{22}$ Fondatorul Bisericii Biblice Global Vision, cu sediul în Muntele Julieta din Tennessee.

${ }^{23}$ Thomas B. Edsall, „The Capitol Insurrection Was as Christian Nationalist as It Gets.' Religious resentment has become a potent recruiting tool for the hard right", în The New York Times, 28 ianuarie 2021, URL: https://www.nytimes.com/2021/01/28/opinion/christian-nationalists-capitolattack.html, accesat la 09.03.2021.

$24 * * *, \ldots$ a rallying of the troops of God's holy army. This is our day. This is our time. This means something for the Kingdom. As a matter of fact, THIS MEANS WAR"; Greg Locke, This Means War: We Will Not Surrender through Silence, Locke Media Publishing, 2020 (apud: Thomas B. Edsall, 'The Capitol Insurrection Was as Christian Nationalist as It Gets'. Religious resentment has become a potent recruiting tool for the hard right, în The New York Times, 28 ianuarie 2021, URL: https://www.nytimes.com/2021/01/28/opinion/christian-nationalists-capitol-attack.html, accesat la 09.03.2021.
}

25 Greg Locke, Twitter account „Pastor Locke”, URL: https://twitter.com/pastorlocke/ status/134647658190 4994309, accesat la 12.03.2021 (apud: Thomas B. Edsall, 'The Capitol Insurrection Was as Christian Nationalist as It Gets' Religious resentment has become a potent 
din data de 12 martie $2021^{26}$.

În 5 ianuarie 2021 a avut loc o procesiune religioasă la Washington, organizată de „fervenți susținători religioși ai președintelui Trump” pe care au denumit-o Jericho March, similar organizației creștine cu același nume. Aceștia fluturau cruci creștine și intonau cântece religioase în timp ce înconjurau Congresul SUA, cerându-i lui Dumnezeu să le ofere ajutorul în cucerirea clădirii, replicând istorisirea biblică a asedierii cetății Ierihonului de către israeliți. ${ }^{27}$ Paralelismul făcut cu Ierihonul biblic este determinat de concepția adepților mișcării Jericho March referitoare la Congresul SUA, și anume că este identic cu Ierihonul, „un oraș al zeilor falși și al corupției”" ${ }^{28}$. Această declarație postată pe propriul site de Jericho March era ștearsă la 11 martie $2021 .^{29}$

În asaltul asupra Congresului American s-au implicat și adepții mișcării de extremă dreapta QAnon. Cu mult înainte de acest moment, teoriile conspiraționiste QAnon referitoare la existența unui ,stat profund satanic și traficant sexual de copii” au modelat credința unor oameni religioși și ,a pregătit trupele de șoc" creștine pentru intervenția împotriva celor care au furat alegerile, convingere devenită ,articol de credinţă”. ${ }^{30}$ De asemenea, printre grupurile de extremă dreapta care s-au manifestat în 6 ianuarie 2021, în asaltul asupra Congresului SUA s-a numărat „Proud Boys" - organizație care susține supremația rasei albe și anterior, în 12 decembrie 2020, membrii grupului participaseră înarmați la un protest la Washington organizat de Jericho March - și „The Three Percenters” - o mișcare militantă de extremă dreapta. ${ }^{31}$

Așadar, atitudinea unor adepți ai creștinismului era de frustrare, tensionată și plină de ură, încă dinainte de asaltul asupra Congresului SUA, în 6 ianuarie 2021, aceștia apelând la resorturile credinței religioase pentru atingerea obiectivelor lor, printre care se regăsește schimbarea orânduirii sociale. Protestatarii au ales Congresul American pentru că reprezintă statul și, conform propriei concepții, pe

recruiting tool for the hard right", în The New York Times, 28 ianuarie 2021, URL: https://www. nytimes.com/2021/01/28/opinion/christian-nationalists-capitol-attack.html, accesat la 09.03.2021.

26 Greg Locke, Twitter account „Pastor Locke”, URL: https://twitter.com/pastorlocke/ status/1346476581904994309, accesat la 12.03.2021.

${ }^{27}$ Harry Farley, „Trump's Christian supporters and the march on the Capitol”, în $B B C$ News, 15 ianuarie 2021, URL: https://www.bbc.com/news/world-us-canada-55578096, accesat la 10.03.2021.

${ }^{28}$ Jericho March, Statement on the Jericho March website, December 2020, URL: https://jerichomarch. org/2020/12/elementor-2213/, accesat la 11.03.2021 (apud: Emma Green, „A Christian Insurrection - Many of those who mobbed the Capitol on Wednesday claimed to be enacting God's will", în The Atlantic, 8, ianuarie 2021, URL: https://www.theatlantic.com/politics/archive/2021/01/evangelicalscatholics-jericho-march-capitol/617591/, accesat la 11.03.2021.

${ }^{29}$ Jericho March, Statement on the Jericho March website, decembrie 2020, URL: https://jerichomarch. org/2020/12/elementor-2213/, accesat la 11.03.2021.

${ }^{30}$ Sarah Posner, art. cit.

${ }^{31}$ Ibidem. 
ei nu îi mai reprezintă, sens în care au considerat că poporul trebuie să reintre în drepturile naturale și să pună stăpânire pe respectiva instituție, fundamentală, de altfel, pentru orice democrație.

\section{Atitudinea membrilor unor congregații creștine în timpul și după asaltul asupra Congresului SUA}

Atitudinea unora dintre participanții religioși la asaltul asupra Congresului SUA a fost una agresivă întrucât erau ferm convinși de corectitudinea demersurilor lor. Chiar și Paula White, consilierul spiritual prezidențial al lui Trump, propaga informații referitoare la „,planuri și rețele demonice care lucrează în numele lui Joe Biden”32, astfel încât, pe timpul marșului „Salvați America” din 6 ianuarie 2021, 1-a invocat pe Dumnezeu ,să dea o îndrăzneală sfântă în această oră și ... să lase orice adversar împotriva democrației, împotriva libertăţii, împotriva vieții, împotriva justiției, împotriva păcii, împotriva dreptății să fie răsturnat chiar acum în numele lui Isus"33. Iar pastorul Darryl Knappen afirma că a fost tentat să poarte haina neagră în ziua respectivă și să-și acopere arma automată (AR-15) sub el ${ }^{34}$, o astfel de retorică militantă nefiind izolată, ci făcând parte din cea a unor lideri creștini.

Membri ai organizației de extremă dreapta Proud Boys, înainte de a merge spre Congresul SUA ,S-au oprit să îngenuncheze pe stradă și s-au rugat în numele lui Isus”. Aceștia au mai cerut de la Dumnezeu „reformă și renaștere” și restabilirea „sistemelor lor de valori”, dar și protecție sacrală în acțiunile viitoare. ${ }^{35}$ De altfel, participanții la asaltul asupra Congresului SUA și-au însușit atât de mult aceste precepte religioase amalgamate cu ideologie politică, încât ,au dărâmat literalmente zidurile guvernului, unii crezând că mărșăluiau sub stindardul lui Isus, pentru a pune în aplicare voința lui Dumnezeu de a-l ține pe Trump în Casa Albă. ${ }^{36}$ Aceștia au purtat steaguri cu simbolistica legată de Iisus, au recitat citate biblice și au susținut predici în difuzoare, asaltul având loc în numele credinței, conform propriilor afirmații ale participanților. ${ }^{37} \mathrm{O}$ parte dintre aceștia au îngenunchiat ritualic și s-au rugat lui Dumnezeu, unii purtau o cruce mare din lemn masiv, alții cântau la shofare, iar alții aveau bannere cu Donald Trump ori conținând dungile alb-roșii și

\footnotetext{
${ }^{32}$ Ibidem.

${ }^{33}$ Sarah Posner, art. cit.

${ }^{34}$ Tom Gjelten, art. cit.

${ }^{35}$ Elizabeth Dias, Ruth Graham, art. cit.

${ }^{36}$ Emma Green, „A Christian Insurrection - Many of those who mobbed the Capitol on Wednesday claimed to be enacting God's will", în The Atlantic, 8 ianuarie 2021, URL: https://www.theatlantic. com/politics/archive/2021/01/ evangelicals-catholics-jericho-march-capitol/617591/, accesat la 11.03.2021.

${ }^{37}$ Ibidem.
} 
stelele albe ale drapelului SUA. ${ }^{38}$ Au fost fluturate și steaguri creștine cu o cruce roșie pe fundal albastru și alb, care simbolizează unitatea tuturor creștinilor din lume ${ }^{39}$, steag promovat începând cu 1897 de mișcarea metodistă din SUA, ,culorile de pe acest steag fiind asemănătoare celui american, albul simbolizând puritatea și pacea, albastrul indicând fidelitatea, iar roșu reprezentând sacrificiul de sânge al lui Hristos" $"$.

Unii dintre participanții la asaltul asupra Congresului SUA au purtat pancarte pe care erau inscripționate mesaje religioase ori simboluri religioase, așa cum este simbolul fundamental al creștinismului, crucea. Se puteau observa pe acestea mesaje ca „Iisus mântuiește” ori "În Dumnezeu avem încredere” ${ }^{41}$ Alte mesaje au fost „ISUS 2020”, ca și cum Iisus Hristos ar fi candidat la alegerile prezidențiale din SUA ${ }^{42}$, „Dumnezeu să binecuvânteze America”"43 și „Faceți din nou America evlavioasă ${ }^{\prime \prime 4}$. Printre pancartele afișate cu ocazia asaltului asupra Congresului SUA din 6 ianuarie 2021 se afla și una pe care scria „Iisus salvează”, fiind identică cu unele observate anterior cu ocazia Jericho March, în 12 decembrie 2020. ${ }^{45}$ Mai mult, în timpul asaltului, au fost fluturate steaguri pe care apăreau desenate arme alături de fraza „Dumnezeu, armele și curajul au construit America, să le menținem pe toate trei”"46, ori sintagma „Armura lui Dumnezeu”"47. Protestatarii au folosit și alte simboluri creștine pe steaguri, un astfel de steag fiind adus în Senatul american, iar un altul pe care era inscripționat „Mândru creștin american” alături de simbolul

\footnotetext{
${ }^{38}$ Harry Farley, art. cit.
}

39 Samuel Perry, „The Capitol siege recalls past acts of Christian nationalist violence”, în The Conversation, 15 ianuarie 2021, URL: https://theconversation.com/the-capitol-siege-recalls-pastacts-of-christian-nationalist-violence-153059, accesat la 11.03.2021.

${ }^{40}$ Elesha Coffman, „Do You Know the History of the Christian Flag? White represents purity and peace, blue indicates fidelity, and red stands for Christ's blood sacrifice", în Christianity Today Christian History, august 2008, URL: https:/www.christianitytoday.com/history/2008/august/doyou-know-history-of-christian-flag.html, accesat la 12.03.2021.

${ }^{41}$ Ed Pilkington, art. cit.

42 Tom Gjelten, „Faith Leaders Nearly Unanimous în Condemning Assault on Capitol”, în NPR, 7 ianuarie 2021, URL: https://www.npr.org/2021/01/07/954581163/faith-leaders-nearly-unanimousin-condemning-assault-on-capitol, accesat la 09.03.2021.

${ }^{43}$ Jon Ward, ,Assault on Capitol was also an attack on Christian faith, Baptist leader Russell Moore says", în Yahoo!news, 15 ianuarie 2021, URL: https://news.yahoo.com/assault-on-capitol-wasalso-an-attack-on-christian-faith-baptist-leader-russell-moore-says-182410188.html, accesat la 09.03.2021.

${ }^{44}$ Sarah Stankorb, „What Place Did Jesus Have at the Capitol Hill Riot? - Pastors who preached Christian nationalism and Trump's promise from God are complicit in this violence", Gen, 9 ianuarie 2021, URL: https://gen.medium.com/jesus-at-the-capitol-attack-5db3601d4ee5, accesat la 12.03.2021.

${ }^{45}$ Tom Gjelten, art. cit.

${ }^{46}$ Emma Green, art. cit.

${ }^{47}$ Elizabeth Dias, Ruth Graham, art. cit. 
de la începuturile creștinismului (IHTIS ${ }^{48}$ ), în interiorul căruia se afla steagul SUA, fiind purtat de alt protestatar. ${ }^{49}$ De altfel, IHTIS reprezenta pentru creștinii primelor veacuri ale erei noastre simbolul divinităţii deoarece era acrostihul hristologic al sintagmei „Iisus Hristos Fiul lui Dumnezeu, Mântuitorul”50.

Dar, pe lângă steaguri și pancarte cu mesaje religioase, protestatarii aveau asupra lor și Biblii, cruci și au reluat în procesiunea lor tema biblică despre cucerirea Ierihonului. ${ }^{51} \mathrm{Au}$ fost adresate inclusiv îndemnuri ca: „Strigă dacă îl iubești pe Iisus”, în timp ce oamenii intrau în clădirea Congresului SUA..$^{52}$ De altfel, și rugăciunea a fost folosită ca instrument de propagandă de către Jacob Chansley, unul dintre așanumiții lideri ai asaltului asupra Congresului SUA, care a solicitat participanților la asalt să se oprească un moment și să se roage la Dumnezeu, protestatarii agreând ideea și strigând ,amin" la final. ${ }^{33}$ Alți participanți au amestecat idealurile creștine cu cele politice; de exemplu, unul dintre aceștia a comentat că „Isus este Mântuitorul meu. Trump este președintele meu" ${ }_{54}$, sintagmă regăsită și pe steaguri, fiind clamat

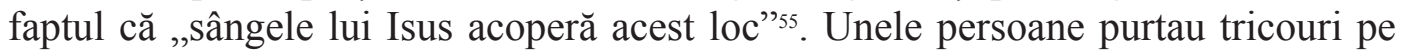
care era inscripționată crucea malteză sau crucea purtată de cavalerii templieri, ${ }^{56}$ care au rămas în istorie ca apărătorii creștinilor și din acest considerent sunt invocați și în prezent.

${ }^{48}$ N.A.: Care înseamnă ,pește” în traducere din limba greacă.

49 Jim Denison, „Was the Capitol riot a "Christian insurrection"? Why we must "live as though the truth were true", în Denison Forum - News Discerned Differently, 11 ianuarie 2021, URL https:// www.denisonforum.org/columns/daily-article/was-the-capitol-riot-a-christian-insurrection-why-wemust-live-as-though-the-truth-were-true/https://www.denisonforum.org/columns/daily-article/wasthe-capitol-riot-a-christian-insurrection-why-we-must-live-as-though-the-truth-were-true/, accessed on accesat la 09.03.2021.

50 Ene Braniște, Ecaterina Braniște, Dicționar Enciclopedic de Cunoștințe Religioase, Editura Diecezană Caransebeș, Caransebeș, 2001, pp. 211-212.

${ }^{51}$ Gregory E. Sterling, „Capitol rioters made a mockery of Christian values”, în CNN, 14 ianuarie 2021, URL: https:/edition.cnn.com/2021/01/14/opinions/capitol-rioters-made-mockery-of-christianitysterling/index.html, accesat la 09.03.2021.

${ }_{52}$ Samuel Perry, art. cit.

${ }^{53}$ Tom Gjelten, art. cit.

${ }^{54} \mathrm{Jim}$ Denison, art. cit.

${ }^{55}$ Matthew Avery Sutton, „The Capitol Riot Revealed the Darkest Nightmares of White Evangelical America - How 150 years of apocalyptic agitation culminated in an insurrection", în The New Republic, 14 ianuarie 2021, URL: https://newrepublic.com/article/160922/capitol-riot-revealeddarkest-nightmares-white-evangelical-america, accesat la 12.03.2021.

${ }^{56}$ Morgan Lee, „Christian Nationalism Is Worse Than You Think - Millions of Americans believe in this political ideology. What church leaders need to know - and how they can help those under its influence", Christianity Today, 13 ianuarie 2021, URL: https://www.christianitytoday.com/ ct/podcasts/quick-to-listen/christian-nationalism-capitol-riots-trump-podcast.htmlhttps://www. christianitytoday.com/ct/podcasts/quick-to-listen/christian-nationalism-capitol-riots-trump-podcast. html, accessed on accesat la 13.03.2021. 
Rețelele de socializare au constituit un element important în propagarea informațiilor și în mobilizarea creștinilor la asaltul asupra Congresului SUA. Spre exemplu, când Franklin Graham spunea, în dimineaţa de 6 ianuarie 2021, că „voturile sunt, dar alegerile s-au terminat? $\mathrm{Nu}$ am niciun indiciu”, acesta era urmărit de peste 9,7 milioane de oameni. Același lider religios mai spunea cu aceeași ocazie: „,cred că trebuie doar să așteptăm și să vedem. Dar știu că trebuie să ne rugăm pentru națiunea noastră. Avem probleme. Cred că vine judecata lui Dumnezeu, pentru că păcatele națiunii noastre sunt mari și sunt o duhoare în nările Creatorului nostru". Postarea avea la 6 martie 2021 peste 62 de mii de comentarii, reacționaseră peste 322 de mii de persoane și fusese distribuită de peste 59 de mii de ori. ${ }^{57}$ De asemenea, unul dintre primii care au intrat ilegal în Congresul SUA a declarat pe Facebook „Trump va fi președintele tău încă patru ani în numele lui Isus" ${ }^{58}$. Într-o postare din 9 ianuarie 2021, pe Facebook, Darryl Knappen făcea apel din propria biserică la patrioții americani să fie gata să se înarmeze și să facă parte dintr-o miliție cetățenească, pentru a-și proteja libertăţile. ${ }^{59}$

Un alt fenomen pe care și l-au însuşit o parte din creștinii participanți la asalt a fost cel al QAnon, mișcare de extremă dreapta a cărui ideologie constă în teorii conspiraționiste. Adepții creștini ai mișcării QAnon au fost prezenți la asaltul asupra Congresului SUA în 6 ianuarie 2021, însușindu-și acuzele nefondate referitoare la fraudarea alegerilor prezidențiale din SUA. „Șamanul QAnon”, Jacob Chansley, cunoscut astfel datorită pălăriei sale cu coarne pe care o poartă la proteste, ,,a rostit o rugăciune" după ritualul creștin, prin care îi mulțumea lui Dumnezeu, ,pentru că a permis Statelor Unite ale Americii să renască”, demers la care au achiesat și alți revoltați. ${ }^{60}$ În timpul rugăciunii, toți cei prezenți au adoptat un comportament pios, semn că aveau însușită o conduită religioasă. ${ }^{61}$ Ridicarea brațelor în aer a protestatarilor în timpul rugăciunii are legătură cu invocarea divinității, dar și ca mulțumire „,pentru că a permis renașterea Statelor Unite ale Americii”. ${ }^{62}$ În același context, veteranul Forțelor Aeriene Ashli Babbitt, împușcată mortal în timpul asaltului asupra Congresului, a fost declarată „,martir” de participanții religioși la asalt. ${ }^{63}$

Contextele și motivele religioase ale atacului asupra Congresului SUA au

\footnotetext{
${ }^{57}$ Franklin Graham, Post on Facebook account “Franklin Graham”, 6 ianuarie 2021, URL: https:// www.facebook.com/FranklinGraham/posts/4023059261083558, accesat la 06.03.2021.

${ }^{58}$ Peter Manseau, art. cit.

${ }^{59}$ Tom Gjelten, art. cit.

${ }^{60}$ Ibidem.

${ }^{61}$ Luke Mogelson, „A Reporter's Video from Inside the Capitol Siege”, in The New Yorker, 01/17/2021, URL: https://www.newyorker.com/video/watch/a-reporters-footage-from-inside-thecapitol-siege, accesat la 09.03.2021.

${ }^{62}$ Sarah Posner, art. cit.

${ }^{63} \mathrm{Jim}$ Denison, art. cit.
} 
constituit un element important în reacţia protestatarilor care au participat la asalt. ${ }^{64}$ Naționalismul creștin a fundamentat ideologic respectivul asalt, creând falsa credință în rândul participanților că ,acțiunile lor au fost binecuvântate de Dumnezeu" ${ }^{65}$. Russell Moore, lider al Convenției Baptiste din Sudul SUA, a afirmat că a fost foarte afectat de faptul că au fost afișate în 6 ianuarie 2021 pancarte pe care scria „Isus mântuiește” alături de „o spânzurătoare” ad-hoc lângă Congresul SUA. Același cleric afirma că astfel de manifestări sunt periculoase întrucât afectează credinţa şi societatea ${ }^{66}$ Mai mult, conform unor interviuri realizate de New York Times, desfășurarea evenimentului din 6 ianuarie 2021, care a constituit apogeul fake-news-urilor referitoare la fraudarea alegerilor prezidențiale de forțe oculte și malefice, ,nu a făcut decât să alimenteze un sentiment mai profund al victimizării și să fie neînțeles" ${ }^{67}$.

Peter Manseau conchide că, deși participanții creștini la asaltul asupra Capitoliului nu reprezintă religia creștină pe ansamblu, creștinii condamnând imediat și ferm ceea ce s-a întâmplat în 6 ianuarie 2021, totuși, din cauza propagării în spațiul public a unor idei politice cu puternice valențe religioase de către unii lideri ai unor importante congregații creștine, s-a ajuns ca în timpul asaltului, creștinii să formeze „nucleul gloatei”, acțiunile lor fiind consecința firească a unei astfel de retorici. ${ }^{68}$ De asemenea, Directorul Institutului Public de Studii Religioase din Washington, Robert P. Jones, spunea că ceea ce s-a întâmplat în Congresul SUA a fost generat de ,amalgamarea ne-sfântă a mișcării supremației albe cu creștinismul”’69. Așadar, religia a determinat comportamentul unei părți a mulțimii care a asaltat Congresul SUA, realizând un act religios în opinia lor, sens în care au expus simboluri creștine ca steaguri de asalt, 1-au invocat pe Dumnezeu cu credința că îndeplinesc voința divină și au replicat ritualuri biblice referitoare la căderea Ierihonului.

\section{Concluzii}

Participanții ultrareligioși la asaltul asupra Congresului SUA au avut credința că au fost chemați de Dumnezeu să cucerească clădirea federală în care funcționează legislativul american. Aceștia s-au comportat astfel, deoarece au crezut că nu există

\footnotetext{
${ }^{64}$ Peter Manseau, art. cit.

${ }^{65}$ Ed Pilkington, art. cit.

${ }^{66}$ Elana Schor, „Christianity on display at Capitol riot sparks new debate”, în AP news, 28 ianuarie 2021, URL:https://apnews.com/article/christianity-capitol-riot-6f13ef0030ad7b5a6f37a1e3b7b4c898, accesat la 06.03.2021.

${ }^{67}$ Elizabeth Dias, Ruth Graham, art. cit.

${ }^{68}$ Peter Manseau, art. cit.

69 Robert P. Jones, Comment on Twitter Account „Religion Media Centre (@RelMedCentre), 7 ianuarie 2021, URL: https://twitter.com/RelMedCentre/status/1347187954079444997, accesat la 09.03.2021.
} 
altă cale de a lupta împotriva unui ,stat profund” "ai cărui reprezentați considerau că se află în respectiva clădire. Demersul politic al asaltului a vizat blocarea certificării ca președinte a lui Joseph Robinette Biden, astfel încât Donald Trump să rămână în funcția de președinte al SUA după 6 ianuarie 2021.

Atât anterior alegerilor prezidențiale din SUA, cât și în timpul asaltului asupra Capitoliului, prin intermediul rețelelor de socializare, au fost propagate informații false despre fraudarea alegerilor care au fost pierdute de președintele Donald Trump. Astfel de informații au fost propagate de lideri religioși importanţi urmăriţi în mediul online de milioane de oameni și ale căror congregații au un foarte mare număr de membri.

Amalgamarea credinței religioase cu ideologie politică a generat o conduită aparte în rândul celor care și le-au însușit. Comportamentul religios a fost direcționat spre modelarea societății conform propriilor viziuni așa cum au fost acestea proiectate de propriile convingeri, astfel de oameni devenind violenți în urmărirea obiectivelor lor. Nimic nu i-a cenzurat în urmărirea atingerii țelului lor de a-1 sprijini pe Donald Trump să rămână în funcția supremă în SUA, pentru un mandat de încă patru ani.

Dominanta religioasă asupra unor participanți la asaltul asupra Congresului SUA este indubitabilă, fiind evidențiată de prezența și arborarea simbolurilor specifice creștinismului, îndeplinirea unor ritualuri religioase, atitudinea și conduita adoptată în timpul rostirii unor rugăciuni, precum și sloganurile, afirmațiile, limbajul și cântecele religioase creștine din timpul evenimentului. Unele dintre persoanele ultrareligioase erau și adepte ale unor teorii conspiraționiste QAnon (precum cea a fraudării alegerilor prezidențiale din 2020), fapt evidențiat în amestecarea simbolurilor creștine cu cele specifice mișcării QAnon și cele ale extremei drepte americane.

Congresul este expresia democrației SUA, iar atacarea sa de oameni ultrareligioși denotă importanța convingerilor religioase în manifestările pe care le au aceștia în anumite situații, ori pe fondul anumitor evenimente pe care le consideră ca fiind un atac la propria persoană, fapt care îi determină să devină frustrați și anxioși. Dorința de a crea instituții administrative aflate numai sub obediența divinității, fără ca cei care le împărtăş̧esc viziunea să aibă puterea de a se opune, nu este nouă în exprimarea ultrareligiozității, aceasta regăsindu-se în istoria creștinismului, finalul acestei dorințe fiind unul violent și sângeros de fiecare dată.

\section{BIBLIOGRAFIE:}

1. ***, ,Book of Esther, Old Testament”, în Britannica, URL: https://www. britannica.com/topic/Book-of-Esther

2. ***, ,Statement from Jericho March”, Jericho March, 14 ianuarie, 2021, URL: https://jerichomarch.org/ 
3. ***, ,Statement on the Jericho March”, Jericho March, decembrie 2020, URL: https://jerichomarch.org/2020/12/elementor-2213/

4. ***, Biblia, Cartea lui Iosua Navi, capitolul 6, versetele 1-11, 16, 20-21, URL: http://www.bibliaortodoxa.ro/carte.php?id=41\&cap $=6$

5. BARBER, Malcolm, The New Knighthood: A History of the Order of the Temple, Cambridge University Press, 1994.

6. BRANIȘTE, Ene, Ecaterina BRANIȘTE, Dicționar Enciclopedic de Cunoștințe Religioase, Caransebeș: Editura Diecezană Caransebeș, 2001.

7. BRODY, David, "EXCLUSIVE: Franklin Graham Tells CBN News He Thinks Democratic Party is 'Opposed to Faith'", în CBN News, 28.08.2020, URL: https://www1.cbn.com/cbnnews/2020/august/exclusive-franklin-graham-tellsnews-he-thinks-democrats-are-opposed-to-faith

8. COFFMAN, Elesha, Do You Know the History of the Christian Flag? White represents purity and peace, blue indicates fidelity, and red stands for Christ's blood sacrifice, în Christianity Today - Christian History, august 2008, URL: https://www. christianitytoday.com/history/2008/august/do-you-know-history-of-christian-flag. html

9. DENISON, Jim, "Was the Capitol riot a "Christian insurrection"? Why we must "live as though the truth were true", în Denison Forum, News Discerned Differently, 11 ianuarie 2021, URL: https://www.denisonforum.org/columns/dailyarticle/was-the-capitol-riot-a-christian-insurrection-why-we-must-live-as-thoughthe-truth-were-true/

10. DIAS, Elizabeth; GRAHAM, Ruth, „How White Evangelical Christians Fused With Trump Extremism - A potent mix of grievance and religious fervor has turbocharged the support among Trump loyalists, many of whom describe themselves as participants in a kind of holy war", în The New York Times, publicat 11 ianuarie, 2021, actualizat 19 ianuarie 2021, URL: https://www. nytimes.com/2021/01/11/us/how-white-evangelical-christians-fused-with-trumpextremism.html

11. EDSALL, Thomas B., „The Capitol Insurrection Was as Christian Nationalist as It Gets.' Religious resentment has become a potent recruiting tool for the hard right", în The New York Times, 28 ianuarie, 2021, URL: https://www. nytimes.com/2021/01/28/opinion/christian-nationalists-capitol-attack.html

12. FARLEY, Harry, Trump's Christian supporters and the march on the Capitol, în BBC News, 15 ianuarie 2021, URL: https://www.bbc.com/news/worldus-canada-55578096

13. GJELTEN, Tom, „Faith Leaders Nearly Unanimous in Condemning Assault on Capitol", în NPR, 7 ianuarie, 2021, URL: https://www.npr.org/ 2021/01/07/954581163/faith-leaders-nearly-unanimous-in-condemning-assault-oncapitol 
14. GJELTEN, Tom, „Militant Christian Nationalists Remain A Potent Force, Even After The Capitol Riot", în NPR, 19 ianuarie, 2021, URL: https://www.npr. org/2021/01/19/958159202/militant-christian-nationalists-remain-a-potent-force

15. GRAHAM, Franklin, Post on Facebook account "Franklin Graham", 6 ianuarie, 2021, URL: https://www.facebook.com/FranklinGraham/posts/ 4023059261083558

16. GREEN, Emma, „A Christian Insurrection - Many of those who mobbed the Capitol on Wednesday claimed to be enacting God's will", în The Atlantic, 8 ianuarie 2021, URL: https://www.theatlantic.com/politics/archive/2021/01/ evangelicals-catholics-jericho-march-capitol/617591/

17. JONES, Robert P., comment on Twitter Account „Religion Media Centre (@RelMedCentre), 7 ianuarie, 2021, URL: https://twitter.com/RelMedCentre/ status/1347187954079444997

18. JUERGENSMEYER, Mark, „The three qualities marking the Capitol assault as terrorism", in Religion Dispatches, 8 ianuarie, 2021, URL: https:// religiondispatches.org/the-three-qualities-marking-the-capitol-assault-asterrorism/

19. LEE, Morgan, „Christian Nationalism Is Worse than You Think - Millions of Americans believe in this political ideology. What church leaders need to know - and how they can help those under its influence", Christianity Today, 13 ianuarie 2021, URL: https://www.christianitytoday.com/ct/podcasts/quick-to-listen/ christian-nationalism-capitol-riots-trump-podcast.html

20. LOCKE, Greg, This Means War: We Will Not Surrender through Silence, Locke Media Publishing, 2020; LOCKE, Greg, Twitter account „Pastor Locke”, URL: https://twitter.com/pastorlocke/status/1346476581904994309

21. MANSEAU, Peter, ,Some Capitol rioters believed they answered God's call, not just Trump's - A relentless religious framing of the election led many Christians to Washington on Jan. 6", în Washington Post, 11 februarie 2021, URL: https://www.washingtonpost.com/outlook/2021/02/11/christian-religioninsurrection-capitol-trump/

22. MOGELSON, Luke, „A Reporter`s Video from Inside the Capitol Siege”, în The New Yorker, 01/17/2021, URL: https://www.newyorker.com/video/watch/areporters-footage-from-inside-the-capitol-siege

23. PERRY, Samuel, ,The Capitol siege recalls past acts of Christian nationalist violence", în The Conversation, January 15, 2021, URL: https://theconversation. com/the-capitol-siege-recalls-past-acts-of-christian-nationalist-violence-153059

24. PILKINGTON, Ed, „Evangelical leaders condemn role of Christian nationalism in Capitol attack", în The Guardian, 24 februarie 2021, URL: https://www.theguardian.com/world/2021/feb/24/evangelical-leaders-christiannationalism-capitol-riot 
25. POSNER, Sarah, „How the Christian Right Helped Foment Insurrection - Christian-right activists inside and outside of government promoted the election fraud lie and claimed God told them to "let the church roar", în Rolling Stone, 31 ianuarie 2021, URL: https://www.rollingstone.com/culture/culture-features/capitolchristian-right-trump-1121236/

26. SCHOR, Elana, „Christianity on display at Capitol riot sparks new debate”, în AP news, 28 ianuarie 2021, URL: https://apnews.com/article/christianity-capitolriot-6f13ef0030ad7b5a6f37a1e3b7b4c898

27. STANKORB, Sarah, „What Place Did Jesus Have at the Capitol Hill Riot? - Pastors who preached Christian nationalism and Trump's promise from God are complicit in this violence", 9 ianuarie 2021, URL: https://gen.medium.com/jesusat-the-capitol-attack-5db3601d4ee5

28. STERLING, Gregory E., „Capitol rioters made a mockery of Christian values", CNN, 14 ianuarie 2021, URL: https://edition.cnn.com/2021/01/14/opinions/ capitol-rioters-made-mockery-of-christianity-sterling/index.html

29. SUTTON, Matthew Avery, „The Capitol Riot Revealed the Darkest Nightmares of White Evangelical America - How 150 years of apocalyptic agitation culminated in an insurrection", The New Republic, 14 ianuarie 2021, URL: https:// newrepublic.com/article/160922/capitol-riot-revealed-darkest-nightmares-whiteevangelical-america

30. WARD, Jon, ,Assault on Capitol was also an attack on Christian faith, Baptist leader Russell Moore says", în Yahoo!news, 15 ianuarie 2021, URL: https:// news.yahoo.com/assault-on-capitol-was-also-an-attack-on-christian-faith-baptistleader-russell-moore-says-182410188.html 